\title{
LA CONVERSIÓN DE LOS FIELES. \\ LA DESVINCULACIÓN ELECTORAL DE LAS \\ CLASES MEDIAS DE LA UNIÓN CÍVICA RADICAL
}

de Gabriel Obradovich,

Buenos Aires, Teseo, 2016, 300 págs.

MARIANA GENÉ

IDAES / UNSAM - CONICET

En un libro profundamente sociológico, Gabriel Obradovich ofrece una investigación detallada sobre la pérdida de apoyo de la Unión Cívica Radical (UCR) entre las clases medias de la Capital Federal. El autor reconstruye los procesos convergentes que llevaron a que aquel bastión tradicional del radicalismo deviniera en un distrito disputado con éxito por otras fuerzas políticas y en el que el partido centenario llegó a la irrelevancia electoral. ¿Qué ocurrió para que la UCR pasara de obtener un promedio histórico cercano al 35\% en las elecciones del distrito, con un récord del $64 \%$ de los votos en 1983, para que llegara luego al $0,8 \%$ de los votos en la peor elección de su historia en 2003? ¿Qué se dio para que se convirtiera en una etiqueta menor que podía pelear alianzas con partidos nuevos en lugar de imponer sus reglas y criterios de lectura del campo político? ¿Cambió el partido? Ciertamente. ¿Las coyunturas históricas fueron decisivas para precipitar ese declive? También, pero no solamente. Obradovich elige contarnos una historia más larga y compleja. Cambiaron además sus votantes, en un período extenso que fue limando las bases de apoyo más nucleares del partido y propiciando un desfasaje entre la organización partidaria y sus electores. Frente a una bibliografía que se concentra en las elites partidarias y las coyunturas políticas, este libro expande el horizonte de indagación y las hipótesis. Por un lado, detalla los cambios estructurales de las clases medias porteñas que contribuyeron a modificar progresivamente las disposiciones y las creencias de los electores radicales, y por esa vía, a desligarlos de las identificaciones que los habían vuelto leales al partido; y por el otro, muestra que, efectivamente, la «conversión de los fieles» se produjo en una coyuntura en la cual el partido se encontraba dividido in- 
ternamente y realizaba una interpelación contradictoria a sus votantes.

Lejos de todo mecanicismo, Obradovich releva la extensa literatura que tematiza la vinculación entre voto y clase, muestra sus límites y desplazamientos. Apoyándose en estudios clásicos, el autor afirma que la UCR tuvo un inicio policlasista y que a partir de 1946 comenzó a adquirir una relación privilegiada con las clases medias. A su vez, trabaja con los distintos antecedentes que muestran los cambios en los sectores medios en el país y en la Ciudad de Buenos Aires en particular, desde su pauperización hasta sus nuevos consumos culturales, señalando matices e inconsistencias, tendencias que irían trastocando la morfología de esa clase y sus modos de pensar y actuar. El libro se apoya sobre una amplia gama de materiales y fuentes de datos: estadísticas, entrevistas en profundidad, archivos partidarios, diarios de tirada nacional, blogs, literatura secundaria y una encuesta realizada por la UCR a más de 22.000 afiliados. Hilvanando con precisión esos distintos elementos, el libro informa sobre un proceso político reciente altamente significativo y a la vez realiza una apuesta teórica clara: contribuir a una visión compleja del voto, que no lo explique por la posición de clase ni por una especie de poder performativo absoluto de la oferta política.

Organizado en diez capítulos, el argumento del libro se despliega de forma pro- gresiva. El primer capítulo retrata grandes «transformaciones estructurales» de las clases medias en la Ciudad de Buenos Aires entre 1990 y 2003. Sistematiza los cambios en la industria y el mercado laboral, mostrando especialmente la caída del comercio barrial y el trabajo familiar, por un lado, y el crecimiento de los nuevos profesionales de servicios, por el otro. Al describir el ascenso de un nuevo tipo de profesional, más desligado de la educación pública y vinculado a nuevos servicios empresariales, Obradovich da cuenta de ciertos procesos de diferenciación en el seno de las clases medias que operarían diversificando sus intereses y expectativas. Aquellos cambios, que sobrepasan con creces a los electores radicales, sirven de marco para comprender las primeras transformaciones de las clases ocurridas en los ańos noventa. Todavía en un nivel macro, el capítulo 2 aborda algunas de las variaciones en los "estilos de vida" de las clases medias. Junto a las transformaciones significativas en la conformación de las familias, se retratan ciertos cambios en los roles de género susceptibles de haber impactado en los modos de socialización política. También se muestra cómo las prestaciones de determinados servicios públicos se vuelven menos centrales para los sectores medios, que poco a poco van cambiando su vínculo con el Estado. Movilizando distintos datos, el capítulo ilumina una lenta pero sostenida trans- 
formación en la concepción de lo público y en el lugar que ocupa en la vida cotidiana de los sectores medios.

Luego de estos capítulos sobre transformaciones de la estructura social e indicadores sobre sus comportamientos, el capítulo 3 aborda específicamente a los votantes radicales, enfocando cambios en sus prácticas políticas y la aparición de nuevas disposiciones que van trastocándolos. Por un lado, aparecen demandas privatistas y críticas frontales al rol del Estado, a tono con el proceso político que estaba en curso a escala nacional, y por el otro se advierte cierta modernización cultural. Junto a esos desplazamientos, se observa una creciente desmovilización de los afiliados del partido en la primera mitad de los años 90, con una baja notable en la participación en las elecciones internas.

El capítulo 4 le da la palabra a esos votantes que cambiaron y también mantuvieron muchos de sus rasgos. Centrado en los esquemas interpretativos de los votantes radicales, este capítulo tiene la virtud de permitirnos escucharlos, seguir sus argumentaciones, percibir el tono y la textura de sus afinidades y sus aversiones. Obradovich nos muestra algunas de las claves que aúnan sus mapas cognitivos: la defensa de la ley y las instituciones, la importancia otorgada a la educación pública y a la historia del radicalismo para garantizarla, la valoración del orden frente al caos, la fuerte alteridad con el peronismo.
Los sistemas simbólicos reconstruidos aquí funcionan como mediadores entre posiciones sociales y discursos partidarios, como un acervo de clasificaciones que orientan la percepción y evaluación del mundo político, y también, finalmente, la acción electoral.

El capítulo 5 va un paso más allá e identifica tipos ideales de votantes radicales. En lugar de aplanar sus diferencias, Obradovich las interroga y nos muestra las singularidades y matices de esos diversos adherentes al partido centenario. Los profesionales tienden a asignarle una supremacía cultural al radicalismo, son antiperonistas y muchos de ellos asocian a la UCR con un movimiento de izquierda en la medida en que se opuso a grandes intereses corporativos. Los pequeños comerciantes e industriales están más alejados del discurso progresista, defienden una ética del trabajo y el esfuerzo individual para progresar frente a las conductas fáciles que buscan mejorar sin esfuerzo, y conciben a la UCR como el partido del orden y la defensa de la ley. Entre los trabajadores poco calificados de clases medias es donde pueden encontrarse las posiciones más recalcitrantes frente al peronismo. Los capítulos 6 y 7 se ocupan de aquellos electores que retiraron su apoyo al radicalismo a partir de la década de 1990. Un conjunto de creencias que aparecían como componentes centrales de sus esquemas interpretativos se debilitaron, 
dando lugar a nuevos modos de percepción y evaluación del mundo social y político. Fundamentalmente, se desvanecieron las expectativas de ascenso social y la creencia en que el partido podía mejorar sus condiciones de vida, se desdibujó el rol acordado al Estado y menguó el antiperonismo. Aquellos esquemas interpretativos que antes aglutinaban a los electores radicales también tenían una función defensiva, nos muestra el autor, en tanto «filtraban» las críticas al partido y proveían explicaciones o justificaciones ante situaciones de crisis. En la década de 1990 aquellas barreras dejaron de darse por supuestas y su función defensiva se volvió menos robusta. Poco a poco otras opciones electorales se volvieron más atractivas para los que ya no serían votantes fieles. La afinidad con el Frente Grande/Frepaso, el voto a Menem en 1995, el voto a la Alianza en 1999 y los desgajamientos en apoyos a las iniciativas de Ricardo López Murphy y Elisa Carrió son analizados desde el punto de vista de los actores, mostrando sus razones y el significado que se le otorgó al hecho de "cambiar el voto" tanto en la citada década de 1990 como en los ańos 2000.

Finalmente, los últimos capítulos del libro atienden al estado de la organización partidaria durante aquellos años de "conversión de los fieles», y al modo en que el partido logró o no reaccionar ante los cambios mayúsculos que se daban en la estructura social y el mundo político. Muestran la fragmentación partidaria en la primera mitad de la década de 1990 y la relativa autonomía del campo político, con la importancia central de las luchas internas para comprender aquel proceso. En esos años en que un ala del partido -con Angeloz a la cabeza- se plegó a las transformaciones emprendidas por el gobierno de Carlos Menem y otra -liderada por Alfonsín- profundizó sus críticas tanto al menemismo como a las fracciones del radicalismo que lo apoyaban, la división partidaria no hizo sino profundizarse y la UCR se vio imposibilitada de acordar un discurso unificado. La exacerbación de la lucha interna frente al Pacto de Olivos produciría un debilitamiento extraordinario en el partido. Contra todo pronóstico, esos enfrentamientos encarnizados terminaron en una alianza entre angelozistas y alfonsinistas para repartirse el poder: Alfonsín quedaría con la presidencia del partido mientras que el cordobés retendría la candidatura a presidente en 1995. Dicha estrategia lograría cerrar el paso a nuevos dirigentes que estaban creciendo (Fernando De la Rúa y Federico Storani) y a la vez amalgamar a aquellos jóvenes que también militaban en bandos opuestos. De ese modo, los clivajes ideológicos fueron perdiendo su peso frente a las luchas, apuestas y acuerdos internos de los dirigentes y sus aliados. Años más tarde, en el período 1996-2001, la alianza con el Frepaso 
se presentaría como una solución estratégica a un partido que ya estaba disgregado. El último capítulo enfoca el ascenso de De la Rúa, los triunfos de la Alianza y la división partidaria del período 1998-2001. Por un lado, identifica las particularidades que adquiere el voto de la UCR cuando aquel es candidato y, por el otro, muestra cómo con esas credenciales De la Rúa logra imponerse al mando de la Alianza y también corona su desmoronamiento.

Por lo dicho, el libro abarca un ciclo largo en que se disgrega el vínculo entre partido y clase social que había caracterizado a gran parte del siglo XX. Con un argumento que va consolidándose capítulo a capítulo, apoyándose en una pluralidad de datos y puntos de observación, el autor nos muestra un fenómeno que se dio con particular ímpetu en la Capital Federal, a diferencia de otras provincias en las que el radicalismo continuó siendo fuerte. En este singular distrito, la convergencia entre cambio social y crisis partidaria aceleró aquel desfasaje entre partido y votantes, los impulsó a caminos diferentes. ¿Qué puede decirse de aquellos fenómenos hoy? En gran parte el libro nos sigue hablando del presente, de la estrategia a la que se libran los dirigentes radicales a nivel nacional y en la propia Ciudad de Buenos Aires, de su política de alianzas y su gestión zigzagueante de las líneas internas, de la fluctuación de sus antiguos votantes y su afinidad con nuevos tipos de interpelaciones. Para todos los que estén interesados en los partidos políticos, en las clases sociales y sus repertorios de acción, en sus esquemas cognitivos y el modo en que median su relación con la política, este libro será una sugerente invitación al pensamiento. 